\title{
Gestantes com COVID-19 e as suas consequências nos recém-nascidos
}

\author{
Pregnant women with COVID-19 and its consequences for newborns \\ Mujeres embarazadas con COVID-19 y sus consecuencias para los recién nacidos
}

\section{Resumo}

A pandemia COVID-19, doença respiratória causada pelo gênero coronavírus, levantou questões quanto à classificação de risco de mulheres gestantes e puérperas. Apesar da grande maioria do grupo se manter assintomática ou com sintomas clássicos da doença (tosse, febre, coriza), a infecção está relacionada ao aumento de eventos adversos da gravidez, como pré-eclâmpsia e ruptura prematura de placenta, além de aumentar as chances de uma morte fetal-intrauterina. Tal problemática reflete-se nos neonatos, os quais podem ser afetados pela contaminação materna, seja pelas maiores chances de prematuridade ou pelo risco de também serem infectados. Sendo assim, objetiva-se por meio deste estudo avaliar na literatura quais as principais consequências registradas do COVID-19 em recém-nascidos de mães infectadas pelo vírus. Para isso, buscou-se pelos descritores nas plataformas Google Scholar, LILACS, PubMED e SciELO, encontrando-se um total de 18736 artigos. Após a aplicação dos critérios de inclusão e de exclusão, restaram 117 artigos para serem analisados, dos quais 26 compõem a amostra atual. A transmissão vertical ainda é pouco relatada, sendo que as manifestações gestacionais mais comuns formam pré-eclâmpsia, sofrimento fetal e parto prematuro. Já em relação aos neonatos, a maioria, quando infectada, não apresenta sintomatologia da doença. Dessa forma, conclui-se que são necessários mais estudos para a confirmação da gravidade do COVID-19 em recém-nascidos de mães positivas, de forma melhorar o entendimento quanto às necessidades e aos cuidados desse grupo.

Palavras-chave: Gravidez; COVID-19; Recém-nascido.

\begin{abstract}
The COVID-19 pandemic, a respiratory disease caused by the coronavirus genus, raised questions regarding the risk classification of pregnant and postpartum women. Although the vast majority of the group remains asymptomatic or with classic symptoms of the disease (cough, fever, runny nose), the infection is related to an increase in adverse pregnancy events, such as pre-eclampsia and premature rupture of the placenta, in addition to increasing the chances of an intrauterine fetal death. This problem is reflected in newborns, which can be affected by maternal contamination, either because of the greater chances of prematurity or the risk of also being infected. Thus, the objective of this study is to evaluate in the literature the main consequences recorded by COVID-19 in newborns of mothers infected with the virus. For this, we searched for the descriptors in the platforms Google Scholar, LILACS, PubMED and SciELO, finding a total of 18736 articles. After applying the inclusion and exclusion criteria, 117 articles remained to be analyzed, of which 26 make up the current sample. Vertical transmission is still poorly reported, with the most common gestational manifestations forming pre-eclampsia, fetal distress and premature birth. In relation to newborns, most, when infected, do not present symptoms of the disease. Thus, it is concluded that further studies are needed to confirm the severity of COVID-19 in newborns of positive mothers, in order to improve the understanding of the needs and care of this group.
\end{abstract}

Keywords: Pregnancy; COVID-19; Newborn. 


\begin{abstract}
Resumen
La pandemia COVID-19, una enfermedad respiratoria causada por el género coronavirus, generó dudas sobre la clasificación de riesgo de las mujeres embarazadas y en posparto. Aunque la gran mayoría del grupo permanece asintomático o con síntomas clásicos de la enfermedad (tos, fiebre, secreción nasal), la infección está relacionada con un aumento de eventos adversos del embarazo, como preeclampsia y rotura prematura de la placenta, en además de aumentar las posibilidades de muerte fetal intrauterina. Este problema se refleja en los recién nacidos, que pueden verse afectados por la contaminación materna, ya sea por las mayores posibilidades de prematurez o por el riesgo de infectarse también. Así, el objetivo de este estudio es evaluar en la literatura las principales consecuencias registradas por COVID-19 en recién nacidos de madres infectadas por el virus. Para ello, se buscaron los descriptores en las plataformas Google Scholar, LILACS, PubMED y SciELO, encontrando un total de 18736 artículos. Tras aplicar los criterios de inclusión y exclusión, quedan por analizar 117 artículos, de los cuales 26 conforman la muestra actual. La transmisión vertical todavía se informa de manera deficiente, y las manifestaciones gestacionales más comunes son preeclampsia, sufrimiento fetal y parto prematuro. En relación a los recién nacidos, la mayoría, cuando se infectan, no presentan síntomas de la enfermedad. Así, se concluye que se necesitan más estudios para confirmar la gravedad de COVID-19 en recién nacidos de madres positivas, con el fin de mejorar la comprensión de las necesidades y cuidados de este grupo.
\end{abstract}

Palabras clave: Embarazo; COVID-19; Recién nacido.

\title{
1. Introdução
}

As infecções respiratórias agudas (IRAs) foram classificadas pela Organização Mundial da Saúde (OMS, 2014) como doenças de alto índice de morbimortalidade em todo o mundo, afetando desde jovens até idosos. Geralmente são causadas por vírus, sendo de alto potencial de propagação, visto que a transmissão se dá principalmente por gotículas contaminadas liberadas no ar. Nesse contexto, em 2019 emergiu uma nova doença respiratória de um gênero viral conhecido como coronavírus. A família do coronavírus é conhecida por causar síndromes respiratórias, como a SARS e a MERS, as quais apresentam uma taxa de letalidade muito inferior quando comparada à atual SARS-CoV-2 (Filho et al., 2017; Brito et al., 2020).

O novo Coronavírus eclodiu na China no final de 2019, mais precisamente na província de Hubei, se espalhando rapidamente por todos os continentes. Já em março de 2020, a Organização Mundial da Saúde (OMS) declarou uma pandemia mundial, sendo o isolamento social o método mais recomendado para evitar a propagação viral. Dentre os sintomas mais comuns, destaca-se a febre, tosse, dificuldade para respirar e coriza, clínica típica de uma síndrome viral. No entanto, em indivíduos imunocomprometidos, como idosos, pacientes com doenças crônicas e hipertensos, a doença pode evoluir para uma síndrome do desconforto respiratório agudo (SDRA), cujo desfecho pode ser letal (Júnior et al., 2020).

Gestantes, lactantes e puérperas são grupos que dividem opiniões quanto à classificação de risco para COVID-19. O Ministério da Saúde brasileiro foi de encontro com a decisão da OMS, e classificou mulheres em tais condições como "grupo de risco", ainda no início de 2020. Apesar de apresentarem um quadro clínico semelhante ao de adultos não gestantes, algumas acabam desenvolvendo complicações severas, afetando tanto a mulher quanto o bebê (Silva et al., 2021; Brasil, 2020).

Ainda que a maioria das gestantes infectadas pelo vírus causador da COVID-19 se mantenham assintomáticas, estudos apontam o aumento da incidência de pré-eclâmpsia, hipertensão, diabetes gestacional e ruptura prematura de placenta. Além disso, os índices de cesáreas e partos prematuros também aumentaram no período de pandemia. Em relação às taxas de internação em Unidades de Terapia Intensiva (UTI), gestantes com COVID-19 evoluíram com maiores chances de admissão em UTIs, apresentando também maiores incidências de morte fetal intrauterina quando comparadas a grávidas não infectadas (Souza et al., 2020; Hcini et al., 2021).

Por possuírem sistema imunológico imaturo, tanto o feto quanto o recém-nascido dependem quase integralmente da imunidade materna. A transmissão vertical do vírus ou de anticorpos vem sendo estudada, não apresentando ainda uma conclusão definitiva. Acredita-se que a maioria dos recém-nascidos infectados contraíram o vírus pós-parto, mesmo a contaminação não sendo comum. Em relação à clínica, grande parte dos neonatos positivos se mantêm assintomática, enquanto 
uma minoria apresenta sintomas como febre, tosse, espirros, taquipneia, distúrbios gastrointestinais e letargia, cuja gravidade está diretamente relacionada à prematuridade (Rondeli et al., 2020; Sociedade de pediatria de São Paulo, 2020).

Sendo assim, o presente estudo tem como objetivo relatar as principais intercorrências que ocorrem em gestantes infectadas pelo coronavírus, se há transmissão vertical intrauterina e suas principais consequências aos recém-nascidos.

\section{Metodologia}

Para realização desta revisão sistemática foram selecionados artigos científicos em maio de 2021, tendo como bancos de dados: Google Scholar, Literatura Latino-americana e do Caribe em Ciências da Saúde (Lilacs), National Library of Medicine (PubMED) e Scientific Electronic Library Online (SciELO). Essas plataformas foram selecionadas por possuírem grande importância na área da saúde, bem como, em virtude de sua disponibilidade de artigos relacionados à temática de interesse, realizadas em uma pesquisa prévia. Para o direcionamento dessa revisão os descritores para essa busca foram: “Recém-nascido e COVID-19”, “Gravidez e COVID-19”’ e “Neonatal COVID-19 infection” (Estrela, 2018).

Foram utilizados como critério para escolha dos artigos aqueles que demonstraram os impactos provocados nos recém-nascidos de mães que durante a gravidez se contaminaram com o novo coronavírus. Vale ressaltar que a busca foi direcionada para artigos publicados nos anos de 2020 e 2021. A amostra inicial bruta constitui-se de 18736 artigos, sendo: 16453 (Google Scholar), 172 (Lilacs), 2076 (PubMed), 35 (SciElo). Após a aplicação dos critérios de escolha, para a execução dessa revisão sistemática, foram lidos 117 resumos; 64 artigos na íntegra através de uma leitura criteriosa e selecionados 26 artigos para incorporação dessa revisão, conforme demonstrado na tabela (Tabela 1).

Tabela 1: Apresentação das referências bibliográficas apanhadas através das bases de dados do Google Scholar, Lilacs, PubMed e SciELO.

\begin{tabular}{|c|c|c|c|c|c|}
\hline $\begin{array}{l}\text { Bases de } \\
\text { Dados }\end{array}$ & Descritores Utilizados & $\begin{array}{l}\text { Número de } \\
\text { Referências } \\
\text { Obtidas }\end{array}$ & $\begin{array}{l}\text { Resumos } \\
\text { Analisados }\end{array}$ & $\begin{array}{l}\text { Referências } \\
\text { Selecionadas } \\
\text { para Análise }\end{array}$ & $\begin{array}{l}\text { Selecionados } \\
\text { para Revisão }\end{array}$ \\
\hline \multirow{3}{*}{$\begin{array}{l}\text { Google } \\
\text { Scholar }\end{array}$} & Recém-nascido e COVID-19 & 793 & 12 & 8 & 5 \\
\hline & Gravidez e COVID-19 & 1960 & 11 & 6 & 4 \\
\hline & Neonatal COVID-19 infection & 13700 & 10 & 5 & 3 \\
\hline \multirow{3}{*}{ Lilacs } & Recém-nascido e COVID-19 & 71 & 15 & 8 & 0 \\
\hline & Gravidez e COVID-19 & 64 & 17 & 9 & 2 \\
\hline & Neonatal COVID-19 infection & 37 & 13 & 7 & 0 \\
\hline \multirow{3}{*}{ PubMed } & Recém-nascido e COVID-19 & 0 & 0 & 0 & 0 \\
\hline & Gravidez e COVID-19 & 3 & 3 & 1 & 1 \\
\hline & Neonatal COVID-19 infection & 2073 & 14 & 9 & 5 \\
\hline \multirow{3}{*}{ Scielo } & Recém-nascido e COVID-19 & 9 & 9 & 5 & 2 \\
\hline & Gravidez e COVID-19 & 14 & 7 & 3 & 3 \\
\hline & Neonatal COVID-19 infection & 12 & 6 & 3 & 1 \\
\hline
\end{tabular}

Fonte: Autores (2021). 


\section{Resultados}

Os estudos sobre a COVID-19 e gravidez não têm sido abordados de forma ampla no período analisado, devido ser um tema sobre uma doença de caráter novo, variável e que ainda não é totalmente conhecido. No ano de 2021 , das 26 publicações analisadas, 16 artigos são de língua inglesa e 10 artigos de língua portuguesa nas bases de dados pesquisadas. Em relação à categoria de estudo, prevalecem os estudos de revisão sistemática.

O Quadro 1 mostra a síntese das referências dos estudos extraídos dos 26 artigos selecionados.

Quadro 1. Características dos artigos escolhidos.

\begin{tabular}{|c|c|c|c|c|}
\hline ID & Título & $\begin{array}{l}\text { País/ } \\
\text { Periódico }\end{array}$ & Objetivo/Desenho metodológico & Desfecho \\
\hline $\begin{array}{l}\text { Elshafeey } \\
\text { et al., } 2020\end{array}$ & $\begin{array}{lr}\text { A } & \text { systematic } \\
\text { scoping } & \text { review of } \\
\text { COVID-19 } & \text { during } \\
\text { pregnancy } & \text { and } \\
\text { childbirth }\end{array}$ & $\begin{array}{l}\text { Inglaterra/ Int } \\
\text { J Gynecol } \\
\text { Obstet }\end{array}$ & $\begin{array}{l}\text { Resumir a literatura existente sobre a } \\
\text { infecção por COVID-19 durante a } \\
\text { gravidez e parto, particularmente no } \\
\text { que se refere à apresentação clínica e } \\
\text { desfechos. Resumo descritivo } \\
\text { organizado por aspectos de } \\
\text { apresentações clínicas e resultados. }\end{array}$ & $\begin{array}{l}\text { A infecção por COVID - } 19 \text { durante a } \\
\text { gravidez provavelmente tem uma } \\
\text { apresentação clínica e gravidade } \\
\text { semelhante à de adultos não grávidas. }\end{array}$ \\
\hline $\begin{array}{l}\text { Guedes et } \\
\text { al., } 2020\end{array}$ & $\begin{array}{l}\text { Aspectos gerais da } \\
\text { COVID-19 na } \\
\text { saúde de gestantes e } \\
\text { recém-nascidos: } \\
\text { Uma breve revisão }\end{array}$ & $\begin{array}{l}\text { Brasil/ } \\
\text { Research, } \\
\text { Society and } \\
\text { Development }\end{array}$ & $\begin{array}{l}\text { Demonstrar as principais informações } \\
\text { acerca do impacto da COVID-19 na } \\
\text { saúde dos recém-nascidos e gestantes. } \\
\text { Revisão narrativa da literatura } \\
\text { científica. }\end{array}$ & $\begin{array}{l}\text { O ideal é permanecer com } r \\
\text { acompanhamentos pré-natais, não } \\
\text { negligenciar a amamentação e o } \\
\text { aleitamento materno, seguindo os } \\
\text { protocolos preconizados pela OMS, para } \\
\text { fortalecer a imunidade dos neonatos. }\end{array}$ \\
\hline $\begin{array}{l}\text { Yang et } \\
\text { al., } 2020\end{array}$ & $\begin{array}{lr}\text { Corona } & \text { virus } \\
\text { disease } & 2019 \\
\text { (COVID-19) and } & \text { and } \\
\text { pregnancy: } & \text { a } \\
\text { systematic review }\end{array}$ & $\begin{array}{l}\text { Inglaterra/ } \\
\text { The Journal of } \\
\text { Maternal- } \\
\text { Fetal \& } \\
\text { Neonatal } \\
\text { Medicine }\end{array}$ & $\begin{array}{l}\text { Resumir as evidências atualmente } \\
\text { disponíveis sobre os resultados } \\
\text { maternos, fetais e neonatais de } \\
\text { mulheres grávidas infectadas com a } \\
\text { doença do Coronavírus } 2019 \\
\text { (COVID-19). Revisão sistemática. }\end{array}$ & $\begin{array}{l}\text { A clínica das grávidas com COVID-19 é } \\
\text { semelhante às de adultos não grávidas. Os } \\
\text { resultados fetais e neonatais parecem } \\
\text { bons, mas os dados incluem apenas } \\
\text { mulheres grávidas infectadas no terceiro } \\
\text { trimestre. Mais estudos são necessários } \\
\text { para determinar os resultados a longo } \\
\text { prazo. }\end{array}$ \\
\hline $\begin{array}{l}\text { co et } \\
20\end{array}$ & $\begin{array}{l}\text { SARS-CoV-2 in } \\
\text { pregnancy: } \\
\text { characteristics and } \\
\text { Outcomes of } \\
\text { hospitalized and } \\
\text { non-hospitalized } \\
\text { Women due to } \\
\text { COVID-19 }\end{array}$ & \begin{tabular}{ll}
\multicolumn{2}{l}{ Inglaterra/The } \\
Journal of \\
Maternal- \\
Fetal \& \\
Neonatal \\
Medicine
\end{tabular} & $\begin{array}{l}\text { Relatar uma série de } 91 \text { mulheres com } \\
\text { diagnóstico de infecção por SARS- } \\
\text { CoV-2 durante a gravidez e o } \\
\text { puerpério. Analisamos } \\
\text { características demográficas, as } \\
\text { condições relacionadas à gravidez e } \\
\text { os sintomas apresentados para } \\
\text { identificar características que } \\
\text { pudessem determinar quais pacientes } \\
\text { necessitarão de hospitalização por } \\
\text { causa do COVID-19 (Grupo 1-G1) e } \\
\text { quais não. Estudo de coorte } \\
\text { retrospectivo. }\end{array}$ & $\begin{array}{l}\text { Os resultados de nossa coorte revelam } \\
\text { que a infecção por SARS-CoV-2 pode } \\
\text { não se comportar de maneira tão branda } \\
\text { quanto sugerida durante a gravidez, } \\
\text { principalmente quando fatores como } \\
\text { obesidade ou origem latina estão } \\
\text { presentes. Nenhuma evidência de } \\
\text { transmissão vertical tardia foi notada, mas } \\
\text { prematuramente cidade e alta taxa de } \\
\text { cesarianas foram achados comuns, } \\
\text { embora seja difícil estabelecer qualquer } \\
\text { causalidade entre essas condições e } \\
\text { COVID-19. }\end{array}$ \\
\hline $\begin{array}{l}\text { Chen et } \\
\text { al., } 2020\end{array}$ & $\begin{array}{l}\text { More on Clinical } \\
\text { Characteristics of } \\
\text { Pregnant Women } \\
\text { with Covid-19 in } \\
\text { Wuhan, China } \\
\end{array}$ & $\begin{array}{l}\text { USA/ The } \\
\text { New England } \\
\text { Journalof } \\
\text { Medicine }\end{array}$ & $\begin{array}{l}\text { Descrever o desfecho entre } 118 \\
\text { pacientes grávidas com COVID-19. } \\
\text { Estudo descritivo. }\end{array}$ & $\begin{array}{l}\text { Foi aconselhado que o parto cesáreo } \\
\text { deveria ser realizado em mulheres com } \\
\text { Covid-19 só depois de uma avaliação } \\
\text { cuidadosa da doença, gravidade e } \\
\text { indicações obstétricas. }\end{array}$ \\
\hline $\begin{array}{l}\text { Chen et } \\
\text { al., } 2020\end{array}$ & $\begin{array}{l}\text { Clinical } \\
\text { characteristics and } \\
\text { intrauterine vertical } \\
\text { ransmission } \\
\text { Potential } \\
\text { COVID-19 of } \\
\text { infection in nine } \\
\text { pregnant women: a } \\
\text { retrospective } \\
\text { review of medical }\end{array}$ & $\begin{array}{l}\text { Reino Unido/ } \\
\text { The Lancet }\end{array}$ & $\begin{array}{l}\text { Avaliar as características clínicas da } \\
\text { COVID-19 na gravidez e no potencial } \\
\text { de transmissão vertical intrauterina da } \\
\text { infecção por COVID-19. Revisão } \\
\text { retrospectiva de registros médicos. }\end{array}$ & $\begin{array}{l}\text { As características clínicas da pneumonia } \\
\text { por COVID-19 em mulheres grávidas } \\
\text { foram semelhantes às relatadas para } \\
\text { pacientes adultas não grávidas que } \\
\text { desenvolveram pneumonia COVID-19. } \\
\text { Nesse estudo não há evidências de } \\
\text { infecção intrauterina causada por } \\
\text { transmissão vertical em mulheres que } \\
\text { desenvolveram pneumonia COVID-19 no } \\
\text { final da gravidez. }\end{array}$ \\
\hline
\end{tabular}




\begin{tabular}{|c|c|c|c|c|}
\hline & records & & & \\
\hline $\begin{array}{l}\text { Godoi et } \\
\text { al., } 2021\end{array}$ & $\begin{array}{l}\text { Clinical Features } \\
\text { and Maternal-fetal } \\
\text { Results of Pregnant } \\
\text { Women in COVID- } \\
19 \text { Times }\end{array}$ & $\begin{array}{l}\text { Brasil/ Rev } \\
\text { Bras Ginecol } \\
\text { Obstet }\end{array}$ & $\begin{array}{l}\text { Identificar e apresentar os principais } \\
\text { estudos sobre gravidez e covid 19, } \\
\text { incluindo o período pós-parto. } \\
\text { Revisão narrativa de literatura. }\end{array}$ & $\begin{array}{l}\text { Grávidas com COVID-19 não } \\
\text { manifestaram clinicamente diferente de } \\
\text { mulheres não grávidas. Em relação aos } \\
\text { fetos, estudos relataram que a infecção } \\
\text { por SARS-CoV-2 em mulheres grávidas } \\
\text { pode causar sofrimento fetal, dificuldades } \\
\text { respiratórias e parto prematuro. }\end{array}$ \\
\hline $\begin{array}{l}\text { Silva et } \\
\text { al., } 2021\end{array}$ & $\begin{array}{lr}\text { Gravidez, } & \text { parto } \\
\text { puerpério } & \text { na } \\
\text { pandemia: } & \text { os } \\
\text { múltiplos } & \text { sentidos } \\
\text { do risco } & \end{array}$ & $\begin{array}{l}\text { Brasil/ Horiz. } \\
\text { antropol. }\end{array}$ & $\begin{array}{l}\text { Analisar a vulnerabilidade materna } \\
\text { em tempo de pandemia e também as } \\
\text { possíveis mudanças que ocorreram no } \\
\text { processo do parto e pós-parto dessas } \\
\text { mulheres. }\end{array}$ & $\begin{array}{l}\text { Três sentidos de risco foram enumerados: } \\
\text { a vulnerabilidade dos corpos de mulheres } \\
\text { grávidas e puérperas; a noção de } \\
\text { contágio; e o problema da mortalidade } \\
\text { materna. }\end{array}$ \\
\hline $\begin{array}{l}\text { Barcelos et } \\
\text { al., } 2020\end{array}$ & $\begin{array}{l}\text { Vertical } \\
\text { Transmission of } \\
\text { SARS-CoV-2:A } \\
\text { Systematic Review }\end{array}$ & $\begin{array}{l}\text { Brasil/ Rev } \\
\text { Bras Ginecol } \\
\text { Obstet }\end{array}$ & $\begin{array}{l}\text { Avaliar a evidência disponível acerca } \\
\text { da transmissão vertical do } \\
\text { coronavírus da síndrome respiratória } \\
\text { aguda grave } 2 .\end{array}$ & $\begin{array}{l}\text { O risco de transmissão vertical pelo vírus } \\
\text { SARS-CoV-2 é provavelmente muito } \\
\text { baixo. }\end{array}$ \\
\hline $\begin{array}{l}\text { Albuquerq } \\
\text { ue et al., } \\
2020\end{array}$ & $\begin{array}{lr}\text { Implicações } & \text { da } \\
\text { COVID-19 para } \\
\text { pacientes gestantes }\end{array}$ & $\begin{array}{l}\text { Brasil/ } \\
\text { Electronic } \\
\text { Journal } \\
\text { Collection } \\
\text { Health }\end{array}$ & $\begin{array}{l}\text { Destacar, através de uma revisão } \\
\text { narrativa, o manejo e medidas de } \\
\text { controle da COVID-19 para as } \\
\text { gestantes e os possíveis riscos durante } \\
\text { a transmissão vertical e a } \\
\text { amamentação. Revisão narrativa. }\end{array}$ & $\begin{array}{l}\text { Conclui que mais procedimentos devem } \\
\text { ser implementados para contornar as } \\
\text { lacunas de conhecimento sobre o efeito } \\
\text { da COVID-19 na gravidez, incluindo } \\
\text { estratégias das vigilâncias sanitária, } \\
\text { epidemiológica, pesquisas } \\
\text { socioeconômicas e soro prevalência. }\end{array}$ \\
\hline $\begin{array}{l}\text { Boaventur } \\
\text { a et al., } \\
2021\end{array}$ & $\begin{array}{l}\text { Covid-19 na } \\
\text { gravidez, parto e } \\
\text { pós-parto imediato: } \\
\text { implicações res e } \\
\text { intercorrências }\end{array}$ & $\begin{array}{l}\text { Brasil/ } \\
\text { Brazilian } \\
\text { Journal of } \\
\text { Development }\end{array}$ & $\begin{array}{l}\text { Verificar as possíveis complicações e } \\
\text { intercorrências da COVID-19 em } \\
\text { mulheres que foram infectadas na } \\
\text { gravidez. Revisão integrativa. }\end{array}$ & $\begin{array}{l}\text { Conclui-se que o parto prematuro e as } \\
\text { indicações de cesárea foram } \\
\text { primordialmente observados em casos } \\
\text { graves da doença. Já as gestantes que } \\
\text { tiveram sintomas leves ou foram } \\
\text { assintomáticas, o parto e a gestação foram } \\
\text { sem intercorrências. }\end{array}$ \\
\hline $\begin{array}{l}\text { Rondelli et } \\
\text { al., } 2020\end{array}$ & $\begin{array}{lr}\text { Assistência } & \text { às } \\
\text { gestantes } & \text { e recém- } \\
\text { nascidos } & \text { no } \\
\text { contexto } & \text { da } \\
\text { infecção } & \text { COVID- } \\
\text { 19: uma } & \text { revisão } \\
\text { sistemática } & \end{array}$ & $\begin{array}{l}\text { Brasil/ } \\
\text { Revista } \\
\text { Desafios }\end{array}$ & $\begin{array}{l}\text { Explorar e sintetizar evidências e } \\
\text { recomendações sobre a atenção e o } \\
\text { manejo de gestantes e recém-nascidos } \\
\text { suspeitos ou confirmados com a } \\
\text { infecção. Revisão sistemática de } \\
\text { estudos observacionais e documentos } \\
\text { oficiais. }\end{array}$ & $\begin{array}{l}\text { Em relação à atenção à saúde das } \\
\text { gestantes e neonatos, o atendimento não } \\
\text { presencial tem sido ferramenta importante } \\
\text { no auxílio à gestão do cuidado na atual } \\
\text { pandemia, possibilitando redução da } \\
\text { aglomeração e superlotação nos serviços } \\
\text { de atenção especializada. }\end{array}$ \\
\hline $\begin{array}{l}\text { Carvalho } \\
\text { et al., } 2021\end{array}$ & $\begin{array}{l}\text { COVID-19: } \\
\text { Uncertainties from } \\
\text { Conception to Birth }\end{array}$ & $\begin{array}{l}\text { Brasil/ Rev } \\
\text { Bras Ginecol } \\
\text { Obstet }\end{array}$ & $\begin{array}{l}\text { Compilar os dados disponíveis sobre } \\
\text { a associação entre a Covid-19 e os } \\
\text { eventos reprodutivos, desde a } \\
\text { concepção até o nascimento. }\end{array}$ & $\begin{array}{l}\text { As informações científicas sobre o } \\
\text { impacto do novo coronavírus, SARS- } \\
\text { CoV-2, na saúde de gestantes, fetos e } \\
\text { recém-nascidos são consideradas de } \\
\text { confiabilidade limitada, sem evidências } \\
\text { de boa qualidade, e levam a conclusões } \\
\text { enviesadas. }\end{array}$ \\
\hline $\begin{array}{l}\text { Singh et } \\
\text { al., } 2021\end{array}$ & $\begin{array}{lr}\text { Maternal and } \\
\text { Neonatal Outcomes } \\
\text { of COVID-19 in } \\
\text { Pregnancy: } & \text { A } \\
\text { Single-Centre } & \\
\text { Observational } \\
\text { Study }\end{array}$ & $\begin{array}{l}\text { USA/ The } \\
\text { Cureus } \\
\text { Journal of } \\
\text { Medical } \\
\text { Science }\end{array}$ & $\begin{array}{l}\text { Avaliar a apresentação clínica de } \\
\text { COVID-19 em gravidez, seu curso } \\
\text { durante a gravidez e seus efeitos } \\
\text { sobre os resultados maternos e } \\
\text { neonatais. Estudo observacional } \\
\text { retrospectivo conduzido em Tata } \\
\text { Main Hospital, Jamshedpur, um } \\
\text { hospital terciário no leste da Índia. }\end{array}$ & $\begin{array}{l}\text { A COVID-19 na gravidez comumente se } \\
\text { apresenta como uma doença } \\
\text { assintomática ou leve. Está associado } \\
\text { com altas taxas de partos prematuros e } \\
\text { admissões neonatais em unidade de } \\
\text { terapia intensiva. Intrauterino e as taxas } \\
\text { de mortalidade neonatal permanecem } \\
\text { baixas. A transmissão vertical é possível; } \\
\text { no entanto, a incidência é baixa, e a } \\
\text { maioria desses neonatos é assintomática. }\end{array}$ \\
\hline $\begin{array}{l}\text { Sousa et } \\
\text { al., } 2020\end{array}$ & $\begin{array}{l}\text { Effects of COVID- } \\
19 \text { Infection during } \\
\text { Pregnancy and } \\
\text { Neonatal Prognosis: } \\
\text { What Is the } \\
\text { Evidence? }\end{array}$ & $\begin{array}{l}\text { Suíça/ Int. J. } \\
\text { Environ. Res. } \\
\text { Public Health }\end{array}$ & $\begin{array}{l}\text { Avaliar as evidências atuais } \\
\text { apresentadas na literatura em relação } \\
\text { aos riscos potenciais de infecção por } \\
\text { COVID-19 entre mulheres grávidas e } \\
\text { consequente transmissão. Revisão } \\
\text { sistemática da literatura. }\end{array}$ & $\begin{array}{l}\text { Não podemos descartar possível piora das } \\
\text { condições clínicas de mulheres grávidas } \\
\text { infectadas com SARS-CoV-2, se a } \\
\text { infecção é associada a comorbidades ou } \\
\text { não, devido à ocorrência de distúrbios } \\
\text { respiratórios, ritmo cardíaco distúrbios e } \\
\text { desequilíbrio acidobásico, entre outros. }\end{array}$ \\
\hline
\end{tabular}




\begin{tabular}{|c|c|c|c|c|}
\hline & & & & $\begin{array}{l}\text { Recomendamos o monitoramento } \\
\text { implacável de todas as mulheres grávidas } \\
\text { além de testá-los antes do parto ou no } \\
\text { primeiro contato com o recém-nascido. }\end{array}$ \\
\hline $\begin{array}{l}\text { Khan et } \\
\text { al., } 2020\end{array}$ & $\begin{array}{l}\text { Impact of COVID- } \\
19 \text { infection on } \\
\text { pregnancy } \\
\text { outcomes and the } \\
\text { risk of maternal- } \\
\text { neonatal intra } \\
\text { partum } \\
\text { transmission of } \\
\text { COVID-19 during } \\
\text { natural birth }\end{array}$ & $\begin{array}{l}\text { USA/ The } \\
\text { Society for } \\
\text { Healthcare } \\
\text { Epidemiology } \\
\text { of America }\end{array}$ & $\begin{array}{l}\text { Apresentar um estudo de relato de } \\
\text { caso em mulheres grávidas }(\mathrm{n}=3) \\
\text { infectado com COVID-19 internado } \\
\text { no Hospital Renmin entre } 28 \text { de } \\
\text { janeiro e } 1 \text { de março de } 2020 \text {. Relato } \\
\text { de caso. }\end{array}$ & $\begin{array}{l}\text { Este estudo de relato de caso foi limitado } \\
\text { por um pequeno tamanho de amostra. } \\
\text { Nenhuma transmissão vertical de } \\
\text { COVID-19 foi encontrada no terceiro } \\
\text { trimestre de gravidez entre bebês nascidos } \\
\text { através da via vaginal. Além disso, não } \\
\text { encontramos evidências de transmissão } \\
\text { intraparto para neonatal de COVID-19 via } \\
\text { vaginal }\end{array}$ \\
\hline $\begin{array}{l}\text { Procianoy } \\
\text { et al., } 2020\end{array}$ & $\begin{array}{l}\text { Neonatal COVID- } \\
\text { 19: little evidence } \\
\text { and the need for } \\
\text { more information }\end{array}$ & $\begin{array}{l}\text { Brasil/ Jornal } \\
\text { de Pediatria }\end{array}$ & $\begin{array}{l}\text { Refletir o } \\
\text { COVID-19 } \\
\text { literatura. }\end{array}$ & $\begin{array}{l}\text { Com base nos relatos disponíveis até o } \\
\text { momento e nos dados científicos } \\
\text { relatados pela China, Itália e pelos } \\
\text { Estados Unidos, os recém-nascidos } \\
\text { parecem ser significativamente menos } \\
\text { afetados pela COVID-19 do que os } \\
\text { adultos. }\end{array}$ \\
\hline $\begin{array}{l}\text { Stofel et } \\
\text { al., } 2021\end{array}$ & $\begin{array}{l}\text { Atenção perinatal } \\
\text { na pandemia da } \\
\text { COVID-19: análise } \\
\text { de diretrizes e } \\
\text { protocolos } \\
\text { nacionais }\end{array}$ & $\begin{array}{l}\text { Brasil/ } \quad \text { Rev. } \\
\text { Bras. Saúde } \\
\text { Matern. } \\
\text { Infant. }\end{array}$ & $\begin{array}{l}\text { Analisar à luz da experiência positiva } \\
\text { na perinatalidade, protocolos e } \\
\text { diretrizes brasileiras acerca da } \\
\text { atenção à saúde perinatal durante a } \\
\text { pandemia da COVID-19. Pesquisa } \\
\text { exploratória de análise documental. }\end{array}$ & $\begin{array}{l}\text { A análise permitiu concluir que a maioria } \\
\text { das recomendações está em consonância } \\
\text { com os preceitos para a experiência } \\
\text { positiva na perinatalidade, mas carecem } \\
\text { de adaptação ao contexto brasileiro. }\end{array}$ \\
\hline $\begin{array}{l}\text { Amorim et } \\
\text { al., } 2021\end{array}$ & $\begin{array}{l}\text { COVID-19 } \\
\text { Gravidez }\end{array}$ & $\begin{array}{l}\text { Brasil/ } \quad \text { Rev. } \\
\text { Bras. } \\
\text { Matern. } \\
\text { Infaúde } \\
\text { Inf. }\end{array}$ & $\begin{array}{l}\text { Revisar a literatura disponível sobre a } \\
\text { COVID-19 e seus aspectos maternos } \\
\text { e perinatais. Revisão narrativa de } \\
\text { literatura. }\end{array}$ & $\begin{array}{l}\text { Conclui-se que é necessário de novos } \\
\text { estudos com mais pesquisa, já que a } \\
\text { maioria são apenas cartas ou pequenas } \\
\text { séries de casos, além de recomendações } \\
\text { de especialistas, sem o rigor científico } \\
\text { necessário. }\end{array}$ \\
\hline $\begin{array}{l}\text { Karimi- } \\
\text { Zarchi et } \\
\text { al., } 2020\end{array}$ & $\begin{array}{lr}\text { Vertical } & \\
\text { Transmission } & \text { of } \\
\text { Coronavirus } & \\
\text { Disease } & 19 \\
\text { (COVID-19) } & \text { from } \\
\text { Infected } & \text { Pregnant } \\
\text { Mothers } & \text { to } \\
\text { Neonates: } & \text { A } \\
\text { Review } & \end{array}$ & $\begin{array}{l}\text { Reino Unido/ } \\
\text { Fetal and } \\
\text { Pediatric } \\
\text { Pathology }\end{array}$ & $\begin{array}{l}\text { Revisar o risco de transmissão } \\
\text { vertical de COVID-19 para o feto de } \\
\text { mães infectadas. Revisão integrativa. }\end{array}$ & $\begin{array}{l}\text { Atualmente, com base em dados } \\
\text { limitados, não há evidências de } \\
\text { transmissão intrauterina de COVID-19 de } \\
\text { mulheres grávidas infectadas para seus } \\
\text { fetos. Mães podem apresentar risco } \\
\text { aumentado de complicações respiratórias } \\
\text { mais graves. }\end{array}$ \\
\hline $\begin{array}{l}\text { Bentlin et } \\
\text { al., } 2020\end{array}$ & $\begin{array}{ll}\text { Coronavírus } & \text { e } \\
\text { recém-nascido: } & \text { o } \\
\text { que se sabe até o } \\
\text { momento? }\end{array}$ & $\begin{array}{ll}\text { Brasil/ } & \\
\text { Sociedade } & \text { de } \\
\text { Pediatria } & \text { de } \\
\text { São Paulo } & \end{array}$ & $\begin{array}{l}\text { Relatar a descoberta de receptores } \\
\text { para proteínas que facilitam a entrada } \\
\text { do vírus para dentro da célula como o } \\
\text { ACE 2 (Angiotensin-converting } \\
\text { enzyme 2) no tecido placentário, } \\
\text { colocam as gestantes em situação de } \\
\text { risco. Diretriz. }\end{array}$ & $\begin{array}{l}\text { As grávidas, ao contrário do que se } \\
\text { imaginava, apresentaram maior risco de } \\
\text { hospitalização, de internação em UTI e de } \\
\text { necessidade de ventilação mecânica } \\
\text { quando comparadas com mulheres de } \\
\text { mesma idade, não grávidas. }\end{array}$ \\
\hline $\begin{array}{l}\text { Cardoso et } \\
\text { al., } 2021\end{array}$ & $\begin{array}{l}\text { A saúde materno- } \\
\text { infantil no contexto } \\
\text { da pandemia de } \\
\text { COVID-19: } \\
\text { evidências, } \\
\text { recomendações e } \\
\text { desafios }\end{array}$ & $\begin{array}{lr}\text { Brasil/ } & \text { Rev. } \\
\text { Bras. } & \text { Saúde } \\
\text { Matern. } & \\
\text { Infant. }\end{array}$ & $\begin{array}{l}\text { Apresentar as principais evidências, } \\
\text { recomendações e desafios à saúde } \\
\text { materno-infantil no contexto da } \\
\text { pandemia de COVID-19. Revisão } \\
\text { narrativa. }\end{array}$ & $\begin{array}{l}\text { O atual momento ainda não nos permite } \\
\text { mensurar as consequências dessa nova } \\
\text { pandemia no âmbito da saúde materno- } \\
\text { infantil, demandando atenção à sua } \\
\text { evolução e novas evidências acerca das } \\
\text { implicações no cuidado ao binômio mãe- } \\
\text { filho. }\end{array}$ \\
\hline $\begin{array}{l}\text { Dube et } \\
\text { al., } 2020\end{array}$ & $\begin{array}{l}\text { COVID-19 in } \\
\text { pregnancy: the fetal } \\
\text { perspective-a } \\
\text { systematic review }\end{array}$ & $\begin{array}{l}\text { Inglaterra/ } \\
\text { BMJ } \\
\text { Pediatrics } \\
\text { Open }\end{array}$ & $\begin{array}{l}\text { Elucidar e analisar os conhecimentos } \\
\text { atuais sobre o impacto da } \\
\text { contaminação pelo vírus durante a } \\
\text { gestação para seu devido } \\
\text { enfrentamento. Realizou-se uma } \\
\text { revisão sistemática. }\end{array}$ & $\begin{array}{l}\text { Achados de transmissão vertical não } \\
\text { foram observados. Apesar de } \\
\text { significativo aumento na realização de } \\
\text { cesáreas, as escolhas devem ser } \\
\text { individualizadas, visto que a infecção por } \\
\text { COVID-19 não é isoladamente indicativa }\end{array}$ \\
\hline
\end{tabular}




\begin{tabular}{|c|c|c|c|c|}
\hline & & & & de intervenção cirúrgica. \\
\hline $\begin{array}{l}\text { Czeresnia } \\
\text { et al., } 2020\end{array}$ & $\begin{array}{l}\text { SARS-CoV-2 and } \\
\text { Pregnancy: A } \\
\text { Review of the Facts }\end{array}$ & $\begin{array}{l}\text { Brasil/ Rev. } \\
\text { Bras. Ginecol. } \\
\text { Obstet. }\end{array}$ & $\begin{array}{l}\text { Fornecer dados objetivos para avaliar } \\
\text { o que se sabe até o momento e } \\
\text { possibilitar uma visão mais ampla dos } \\
\text { efeitos do SARS- CoV } 2 \text { na gravidez. } \\
\text { Revisão de literatura. }\end{array}$ & $\begin{array}{l}\text { Os fatores que estão associados à maior } \\
\text { morbidade materno-fetal são: obesidade } \\
\text { (índice de massa corporal [IMC] > 35), } \\
\text { asma e doença cardiovascular. Há } \\
\text { descrição de aumento de parto prematuro } \\
\text { e parto cesáreo. Não se pode descartar a } \\
\text { possibilidade de transmissão vertical da } \\
\text { doença, devido a relatos de positividade } \\
\text { de reação em cadeia de polimerase (RT- } \\
\text { PCR) de Swab nasal, RT-PCR de líquido } \\
\text { amniótico e imunoglobulina M (IgM) de } \\
\text { recém-nascidos. }\end{array}$ \\
\hline $\begin{array}{l}\text { Crispim et } \\
\text { al., } 2020\end{array}$ & $\begin{array}{l}\text { Infecção por } \\
\text { COVID-19 durante } \\
\text { a gestação: } \\
\text { Avaliação das } \\
\text { manifestações } \\
\text { clínicas e desfecho } \\
\text { gestacional }\end{array}$ & $\begin{array}{l}\text { Brasil/Rev. } \\
\text { Ciênc. Saúde } \\
\text { Nova } \\
\text { Esperança. }\end{array}$ & $\begin{array}{l}\text { Elucidar e analisar os conhecimentos } \\
\text { atuais sobre o impacto da } \\
\text { contaminação pelo vírus durante a } \\
\text { gestação para seu devido } \\
\text { enfrentamento. Realizou-se uma } \\
\text { revisão sistemática. }\end{array}$ & $\begin{array}{l}\text { As complicações gestacionais mais } \\
\text { relatadas foi sofrimento fetal, ruptura } \\
\text { prematura de membranas, partos } \\
\text { prematuros e até mesmo morte fetal. } \\
\text { Todavia, achados de transmissão vertical } \\
\text { não foram observados. Apesar de } \\
\text { significativo aumento na realização de } \\
\text { cesáreas, as escolhas devem ser } \\
\text { individualizadas, visto que a infecção por } \\
\text { COVID-19 não é isoladamente indicativa } \\
\text { de intervenção cirúrgica. }\end{array}$ \\
\hline $\begin{array}{l}\text { Castro et } \\
\text { al., } 2020\end{array}$ & $\begin{array}{l}\text { Covid-19 } \quad \text { and } \\
\text { Pregnancy: } \\
\text { Overview }\end{array}$ & $\begin{array}{l}\text { Brasil/ Rev. } \\
\text { Bras. Ginecol. } \\
\text { Obstet. }\end{array}$ & $\begin{array}{l}\text { Fornecer uma breve análise de } \\
\text { gravidez na era COVID-19, e os } \\
\text { efeitos da COVID-19 na gravidez. } \\
\text { Revisão de literatura. }\end{array}$ & $\begin{array}{l}\text { Conclui-se que as consequências de um } \\
\text { período de intenso estresse e ansiedade } \\
\text { durante gravidez pode resultar em como } \\
\text { trabalho de parto prematuro espontâneo. }\end{array}$ \\
\hline
\end{tabular}

Fonte: Autores (2021).

Os resultados obtidos e interpretados através da análise dos artigos escolhidos, foram unânimes ao relatar que ainda não há evidências suficientes para saber qual a relação do novo Coronavírus e as gestantes. As complicações gestacionais mais relatadas foram: sofrimento fetal, ruptura prematura de membranas, partos prematuros e até mesmo morte fetal. Porém, existem muitos fatores psicológicos que envolvem o contexto dessa nova doença e a gestação (Crispim et al., 2020).

De acordo com o quadro acima, pode-se constatar que seis desses artigos referem a situações específicas de um estudo observacional, sendo um deles um relato de caso. Nota-se, a dificuldade de encontrar estudos retrospectivos com tal análise. Ainda, teve trabalhos que falaram sobre o manejo de gestantes e recém-nascidos suspeitos ou confirmados com a infecção.

Mediante análise sistemática dos estudos, os vinte e seis artigos caracterizaram demonstrar e analisar os conhecimentos gerais e atuais sobre o impacto da contaminação pelo vírus durante a gestação para seu combate. Ainda, há um artigo que procura identificar as consequências dessa nova pandemia no âmbito da saúde materno-infantil.

\section{Discussão}

Devido a contemporaneidade do Coronavírus, que é causador da pandemia da COVID-19, muitos estudos ainda estão em curso sobre a relação desse agente patogênico e seu impacto nas gestantes. Desse modo, fica claro que ao longo do tempo teremos acesso a mais pesquisas e consequentemente a mais artigos sobre o tema em relação aos que possuímos no dia de hoje (Cardoso et al., 2021). O caráter global e o crescente interesse e incentivo monetário pelo assunto, está mobilizando pesquisadores e cientistas a trazerem respostas para as perguntas da interação desse vírus a gestantes e recém-nascidos (Albuquerque et al., 2020).

O primeiro ponto a ser citado é que a infecção pelo coronavírus durante a gravidez tem uma apresentação clínica e gravidade semelhante à de adultos não grávidas (Elshafeey et al., 2020; Godoi et al., 2021). As características clínicas da pneumonia pela doença em mulheres grávidas foram semelhantes às relatadas para pacientes adultas não grávidas que 
desenvolveram pneumonia causada pela COVID-19 (Chen et al., 2020). Essas afirmações foram confrontadas no artigo publicado por Silva (2021), que aponta fatores além dos patológicos da infecção, como o estado psicológico e o afastamento das atividades diárias - tecendo reflexões sobre os paradoxos e tensões que a caracterização como "grupo de risco" pode representar para a assistência humanizada e para a vida reprodutiva das mulheres brasileiras.

A transmissão vertical intrauterina é algo que não está claro nos estudos analisados (Yang et al., 2020). Contudo, estudos pioneiros demonstram que não houve transmissão intrauterina em gestantes (Karimi-Zarchi et al., 2020; Dube et al., 2020; Chen et al., 2020). Já outros artigos defendem que essa infecção não acontece com os fetos de gestantes que foram diagnosticadas com o vírus durante o terceiro trimestre de gravidez (Chen et al., 2020; Khan et al., 2020). No Karimi-Zarchi (2020) e no Barcelos (2020), existe a clara conotação que esses dados analisados são oriundos de casos limitados e em baixo número, caracterizando a importância da necessidade de maiores amostras para a conclusão e a exposição de uma conclusão final.

De acordo com o Czeresnia (2020) e o Singh (2021), a infecção intrauterina é possível, no entanto, a incidência é baixa, e a maioria desses neonatos é assintomática. Isso acontece devido a relatos de positividade de reação em cadeia de polimerase (RT-PCR) de líquido amniótico e imunoglobulina M (IgM) de recém-nascidos (Czeresnia et al., 2020). Esses são dois estudos que contradizem os estudos citados acima e que demonstram por sorologia a contaminação do líquido amniótico e do feto.

A transmissão vertical extrauterina no parto vaginal não foi identificada em uma pequena amostragem de gestantes infectadas no terceiro trimestre (Khan et al., 2020). Cabe citar, que gestantes com COVID-19 não possuem indicação ao parto cesárea (Dube et al., 2020; Boaventura et al., 2021), apenas após uma avaliação obstétrica essa opção pode ser aconselhada (Chen et al., 2020). Novamente, o Czeresnia (2020) acrescenta a discussão evidenciando o aumento de partos prematuros e as indicações de parto cesárea em gestantes contaminadas com o Sars-CoV-2.

De acordo com Godoi (2021), a infecção pelo vírus da COVID-19 em mulheres grávidas pode causar sofrimento fetal, dificuldades respiratórias e parto prematuro. Isso é apoiado pelo artigo de Crispim (2020) mostra o aumento na pandemia das complicações gestacionais como o sofrimento fetal, a ruptura prematura de membranas e até mesmo morte fetal como os fatores responsáveis pelo aumento das cesáreas nesse período. Esse trabalho ainda soma ao citar que as escolhas devem ser individualizadas às gestantes, visto que a infecção pelo Coronavírus não é isoladamente indicativa de intervenção cirúrgica.

Gestantes com comorbidades como obesidade (índice de massa corporal [IMC] > 35), asma e doenças cardiovasculares são fatores que estão associados à maior morbidade materno-fetal (Czeresnia et al., 2020).Não podemos descartar possível piora das condições clínicas de mulheres grávidas infectadas pelo vírus da COVID-19, se a infecção é associada a comorbidades ou não, devido à ocorrência de distúrbios respiratórios, ritmo cardíaco distúrbios e desequilíbrio ácido-básico, entre outros (Sousa et al., 2020).

Castro (2020) cita que os fatores psicológicos de estresse e ansiedade trazidos pela pandemia também influenciam em partos prematuros de gestantes infectadas e não infectadas pelo vírus e frisa que deve ser reservada uma maior atenção para as grávidas neste momento de um sistema de saúde sobrecarregado e trabalhadores de saúde exaustos - visando à proteção do recém-nascido, da família e da própria equipe da saúde.

A transmissão do vírus pela amamentação é outra dúvida que ainda permanece nos artigos analisados, Guedes (2020) aponta que o aleitamento materno deve seguir as recomendações da Organização Mundial da Saúde. De acordo com Barbero (2020), nenhuma transmissão vertical tardia foi notada em seu estudo, dando a credibilidade ao aleitamento materno.

Em relação à atenção à saúde das gestantes e neonatos, o atendimento não presencial tem sido ferramenta importante no auxílio à gestão do cuidado na atual pandemia, possibilitando redução da aglomeração e superlotação nos serviços de atenção especializada (Rondelli et al., 2020). Mesmo que dados científicos relatados pela China, Itália e pelos Estados Unidos, 
evidenciam que recém-nascidos parecem ser significativamente menos afetados pela COVID-19 do que os adultos (Procianoy et al., 2020), porém, no Brasil ainda falta dados sobre esse tipo de pesquisa (Stofel et al., 2021).

\section{Conclusão}

Presente a todo o exposto, está claro que há mais de um ano o coronavírus tem sido o principal foco de pesquisa dos estudiosos ao redor do mundo, contudo, conclui-se que as descobertas sobre influência da COVID-19 nas gestantes fluem conforme a pandemia se dissemina e se expõe as diversas áreas de pesquisas sobre o tema, não existindo um veredito postulado do que é certo neste momento. Diante disso, cabe tratar a situação como uma emergência viral, prezando o distanciamento social e o uso de equipamentos de proteção individuais enquanto se busca as respostas sobre o comportamento do vírus sobretudo as gestantes em favor a própria saúde e da saúde de suas futuras proles que até o momento lutam com um mar de incertezas. No futuro, aguardamos trabalhos com enfoque centrado neste tema. É necessário a investigação e a análise em grande número da infecção por coronavírus em gestantes e as repercussões em recém-nascidos. Essa é uma discussão que deverá ir além da pandemia e do surgimento das variantes desse vírus, pois as suas consequências podem ser imediatas ou tardias na vida dos nascidos durante esse tempo. Desse modo, portanto, torna-se claro a importância dos estudos apresentados, é necessário conhecer as influências causadas por uma gestação com o diagnóstico de COVID-19 aos gestados, explorando as manifestações a curto, a médio e a longo prazo em suas vidas.

\section{Referências}

Amorim, M. M. R., Souza, A. S. R., Melo, A. S. D. O., Delgado, A. M., Florêncio, A. C. M. C. D. C., Oliveira, T. V. D., \& Katz, L. (2021). COVID-19 e Gravidez. Revista Brasileira de Saúde Materno Infantil, 21, 337-353.

Barbero, P., Mugüerza, L., Herraiz, I., García Burguillo, A., San Juan, R., Forcén, L., \& Galindo, A. (2020). SARS-CoV-2 in pregnancy: characteristics and outcomes of hospitalized and non-hospitalized women due to COVID-19. The Journal of Maternal-Fetal \& Neonatal Medicine, 1-7.

Bentlin, M. R., de Almeida, M. F. B., Marba, S. T. M., Guinsburg, R., Rebello, C. M., de Siqueira Caldas, J. P., \& do Nascimento, S. D. Coronavírus E Recém-Nascido: O Que Se Sabe Até O Momento? Versão 3.

Boaventura, M. D., Costa, M. R., Nunes, R. N., Santo Carine, C. S. C. S., Santos, S., Sampaio, I. L., \& Moura, L. R. (2021). Covid-19 na gravidez, parto e pós-parto imediato: implicações e intercorrências. Brazilian Journal of Development, 7 (7), 73368-73382.

Brasil, Ministério da Saúde (2020). Recomendação nº 035 de 12 de maio de 2020.

Brito, S. B. P. et al. (2020). Mecanismos imunopatológicos envolvidos na infecção por SARS-CoV-2. Jornal Brasileiro de Patologia e Medicina Laboratorial, 56, e3352020, 2020.

Cardoso, P. C., Sousa, T. M. D., Rocha, D. D. S., Menezes, L. R. D. D., \& Santos, L. C. D. (2021). A saúde materno-infantil no contexto da pandemia de COVID-19: evidências, recomendações e desafios. Revista Brasileira de Saúde Materno Infantil, 21, 213-220.

Carvalho, B. R. D., Adami, K. D. S., Gonçalves-Ferri, W. A., Samama, M., Ferriani, R. A., \& Marcolin, A. C. (2021). COVID-19: Uncertainties from conception to birth. Revista Brasileira de Ginecologia e Obstetrícia, 43, 54-60.

Castro, P., Matos, A. P., Werner, H., Lopes, F. P., Tonni, G., \& Araujo Júnior, E. (2020). Covid-19 and Pregnancy: An Overview. Revista Brasileira de Ginecologia e Obstetrícia, 42 (7), 420-426.

Chen, H., Guo, J., Wang, C., Luo, F., Yu, X., Zhang, W., \& Zhang, Y. (2020). Clinical characteristics and intrauterine vertical transmission potential of COVID-19 infection in nine pregnant women: a retrospective review of medical records. The lancet, 395(10226), 809-815.

Chen, L., Li, Q., Zheng, D., Jiang, H., Wei, Y., Zou, L., \& Qiao, J. (2020). Clinical characteristics of pregnant women with Covid-19 in Wuhan, China. New England Journal of Medicine, 382 (25), e100.

Crispim, M. E. S., Frade, A. C., de Vasconcellos, C. A. Neto, J. R. F., \& de Brito, M. B. R. (2020). Infecção Por Covid-19 Durante A Gestação: Avaliação Das Manifestações Clínicas E Desfecho Gestacional. Revista de Ciências da Saúde Nova Esperança, 18 (3), $214-222$.

Czeresnia, R. M., Trad, A. T. A., Britto, I. S. W., Negrini, R., Nomura, M. L., Pires, P., \& Ruano, R. (2020). SARS-CoV-2 and Pregnancy: A Review of the Facts. Revista Brasileira de Ginecologia e Obstetrícia, 42 (9), 562-568.

de Albuquerque, L. P., Monte, A. V. L., \& de Araújo, R. M. S. (2020). Implicações da COVID-19 para pacientes gestantes. Revista Eletrônica Acervo Saúde, 12 (10), e 4632-e 4632. 
Research, Society and Development, v. 10, n. 12, e303101220506, 2021 (CC BY 4.0) | ISSN 2525-3409 | DOI: http://dx.doi.org/10.33448/rsd-v10i12.20506

Deniz, M., \& Tezer, H. (2020). Vertical transmission of SARS CoV-2: a systematic review. The Journal of Maternal-Fetal \& Neonatal Medicine, 1-8.

dos Santos Guedes, B. L. C., do Nascimento, A. K. P., Melo, B. T. G., da Cunha, S. M. D. de Oliveira Filho, A. A., \& de Oliveira, H. M. B. F. (2020). Aspectos gerais da COVID-19 na saúde de gestantes e recém-nascidos: Uma breve revisão. Research, Society and Development, 9 (7), e897974969e897974969.

Dube, R., \& Kar, S. S. (2020). COVID-19 in pregnancy: the fetal perspective-a systematic review. BMJ pediatrics open, 4 (1).

Elshafeey, F., Magdi, R., Hindi, N., Elshebiny, M., Farrag, N., Mahdy, S., \& Nabhan, A. (2020). A systematic scoping review of COVID-19 during pregnancy and childbirth. International Journal of Gynecology \& Obstetrics, 150 (1), 47-52.

Estrela, C. (2018). Metodologia Científica: Ciência, Ensino, Pesquisa. Editora Artes Médicas.

Filho, E. B. S. et al. (2017). Infecção respiratória de importância clínica: uma revisão sistemática. Revista FIMCA, 4 (1), 7 -16.

Godoi, A. P. N., Bernardes, G. C. S., S. Nogueira, L. S., Alpoim, P. N., \& Pinheiro, M. D. B. (2021). Clinical Features and Maternal-fetal Results of Pregnant Women in COVID-19 Times. Revista Brasileira de Ginecologia e Obstetrícia, 43, 384-394.

Hcini, N. et al. (2020). Maternal, fetal and neonatal outcomes of large series of SARS-CoV-2 positive pregnancies in peripartum period: A single-center prospective comparative study. European Journal of Obstetrics, Gynecology and Reproductive Biology, 257, 11-18.

Karimi-Zarchi, M., Neamatzadeh, H., Dastgheib, S. A., Abbasi, H., Mirjalili, S. R., Behforouz, A., ... \&Bahrami, R. (2020). Vertical transmission of coronavirus disease 19 (COVID-19) from infected pregnant mothers to neonates: a review. Fetal and pediatric pathology, 39 (3), $246-250$.

Khan, S., Peng, L., Siddique, R., Nabi, G., Xue, M., Liu, J., \& Han, G. (2020). Impact of COVID-19 infection on pregnancy outcomes and the risk of maternal-to-neonatal intrapartum transmission of COVID-19 during natural birth. Infection Control \& Hospital Epidemiology, 41 (6), 748 -750.

Lopes de Sousa, À. F., Carvalho, H. E. F. D'Oliveira, L. B. D. Schneider, G., Camargo, E. L. S., Watanabe, E., ... Fronteira, I. (2020). Effects of COVID-19 infection during pregnancy and neonatal prognosis: what is the evidence? International journal of environmental research and public health, 17 (11), 4176.

Macedo-Júnior, A. M. (2020). Covid-19: calamidade pública. Medicus, 2, (1), 1-6, 2020.

Procianoy, R. S., Silveira, R. C., Manzoni, P., \&Sant'Anna, G. (2020). Neonatal COVID-19: little evidence and the need for more information. Jornal de pediatria, 96(3), 269-272.

Rondelli, G., Jardim, D., Hamad, G., Luna, E., Marinho, W., Mendes, L., \& Gratão, L. (2020). Assistência às gestantes e recém-nascidos no contexto da infecção COVID-19: uma revisão sistemática. Desafios-Revista Interdisciplinar da Universidade Federal do Tocantins, 7 (Especial-3), $48-74$.

Silva, F. L. et al. (2021). Gravidez, parto e puerpério na pandemia: os múltiplos sentidos do risco. Horizontes Antropológicos, 27, (59), $245-265$, 2021.

Singh, V., Choudhary, A., Datta, M. R., \& Ray, A. (2021). Maternal and Neonatal Outcomes of COVID-19 in Pregnancy: A Single-Centre Observational Study. Cureus, 13 (2).

Sociedade de Pediatria de São Paulo. (2020). Coronavírus e recém-nascido: o que se sabe até o momento?

Souza, H. C. C. et al. (2020) COVID-19 e gestação: manifestações clínicas, alterações laboratoriais e desfechos maternos, uma revisão sistemática de literatura. Brazilian Journal of Health Review, 3 (6), 15901-15918.

Stofel, N. S., Christinelli, D., Silva, R. C. D. S., Salim, N. R., Beleza, A. C. S., \& Bussadori, J. C. D. C. (2021). Atenção perinatal na pandemia da COVID-19: análise de diretrizes e protocolos nacionais. Revista Brasileira de Saúde Materno Infantil, 21, 89-98.

Yang, Z., Wang, M., Zhu, Z., \& Liu, Y. (2020). Coronavirus disease 2019 (COVID-19) and pregnancy: a systematic review. The Journalof Maternal-Fetal \& Neonatal Medicine, 1-4. 